\title{
Synthesis and chemistry of chromium in CrAPO-5 molecular sieves
}

\author{
Bert M. Weckhuysen and Robert A. Schoonheydt \\ Centrum voor Opperulaktechemie en Katalyse, K.U. Leuven, Heverlee, Belgium
}

\begin{abstract}
CrAPO-5 molecular sieves were synthesized hydrothermally starting with different $\mathrm{Cr}$ precursors and $\mathrm{Cr}$ and template contents. The behavior of $\mathrm{Cr}$ was investigated spectroscopically by diffuse reflectance spectroscopy (d.r.s.) and electron spin resonance (e.s.r.). In the gels, $\mathrm{Cr}^{3+}$ and $\mathrm{Cr}^{6+}$ are present as, respectively, octahedral $\mathrm{Cr}\left(\mathrm{H}_{2} \mathrm{O}\right)_{6}^{3+}$ and mainly dichromate. Both ions are in the liquid phase of the gels. In all as-synthesized $\mathrm{CrAPO}-5^{\prime} \mathrm{s}, \mathrm{Cr}^{3+}$ is octahedrally coordinated to six oxygen ligands. The corresponding e.s.r. spectra show a broad isotropic signal centered around 1.97, following the Curie-Weiss law. This behavior is comparable with $\mathrm{Cr}^{3+}$ impregnated on AIPO-5 and assigned to hexa-aquo $\mathrm{Cr}^{3+}$ ions. Upon calcination, this signal decreases in intensity, a new sharp signal of $\mathrm{Cr}^{5+}$ is formed, and, in d.r.s., $\mathrm{Cr}^{6+}$ is formed at the expense of $\mathrm{Cr}^{3+}$. However, the broad e.s.r. signal of $\mathrm{Cr}^{3+}$ does not follow the Curie-Weiss law and is due to $\mathrm{Cr}^{3+}$ clusters. $\mathrm{Cr}^{6+}$ and $\mathrm{Cr}^{5+}$ are easily reduced with $\mathrm{CO}$ to octahedral $\mathrm{Cr}^{3+}$ and octahedral and tetrahedral $\mathrm{Cr}^{2+}$, whereas recalcination reestablishes the original $\mathrm{Cr}^{6+}$ and $\mathrm{Cr}^{5+}$ species. All these results support the idea that $\mathrm{Cr}^{3+}$ is not incorporated into the framework, but is present as octahedral ions at the surface of the AIPO-5 crystals.
\end{abstract}

Keywords: CrAPO-5; isomorphous substitution; microporous aluminophosphates; synthesis; d.r.s.; e.s.r.

\section{INTRODUCTION}

Metal-substituted aluminophosphate molecular sieves, denoted with the acronym MeAPO's, ${ }^{1}$ have received extensive attention from researchers working in the area of molecular sieve science and shapeselective catalysis. Isomorphous substitution of metal ions (Me) in inorganic solids, such as AlPO-5, is an important reaction, which allows control of acidity and cation-exchange capacity. ${ }^{2}$ Isomorphic substitution of $\mathrm{Al}^{3+}$ and/or $\mathrm{P}^{5+}$ has been claimed for a variety of elements such as $\mathrm{Ga}, \mathrm{Ge}, \mathrm{B}, \mathrm{As}, \mathrm{Si}, \mathrm{Ti}, \mathrm{Fe}$, and $\mathrm{Co}^{3}$

In the patent literature, ${ }^{4}$ the synthesis of CrAPO-5 has been reported, but the question remains if $\mathrm{Cr}^{3+}$ substitutes for $\mathrm{Al}^{3+}$ in the framework and to what extent. Isomorphous substitution requires tetrahedral $\mathrm{Cr}^{3+}$, which is difficult to obtain. This is evidenced by the scarcity of tetrahedral $\mathrm{Cr}^{3+}$ complexes ${ }^{5}$ and the absence of reported inorganic structures with tetrahedral $\mathrm{Cr}^{3+} .6$ Recently, Rajic et al. ${ }^{7}$ studied the possibility of incorporation of $\mathrm{Cr}^{3+}$ into a chabazitetype aluminophosphate lattice (SAPO-34), but concluded that no $\mathrm{Cr}^{3+}$ was incorporated into the framework. Up to now, no paper has been devoted to a detailed spectroscopic study of this substitution reaction and of the chemistry of CrAPO-n's.

This is the starting point of this research work. We

Address reprint requests to Mr. Weckhuysen at the Centrum voor Oppervlaktechemie en Katalyse, K.U. Leuven, Kardinaal Mercierlaan 92, B-3001 Heverlee, Belgium.

Received 14 September 1993; accepted 20 January 1994 have synthesized series of CrAPO-5 molecular sieves with increasing $\mathrm{Cr}$ content and studied the effect of synthesis time, synthesis temperature, and $\mathrm{Cr}$ sources. Both as-synthesized and calcined samples were spectroscopically investigated by diffuse reflectance spectroscopy (d.r.s.) and electron spin resonance (e.s.r.). The wet precursor gels were investigated with d.r.s. and the coordination chemistry of $\mathrm{Cr}$ was unraveled after calcination, $\mathrm{CO}$ reduction, and recalcination.

\section{EXPERIMENTAL}

\section{Synthesis procedure}

CrAPO-5 was synthesized following a modified method of Flanigen et al. ${ }^{4}$ A chromium source was added to a solution of $\mathrm{H}_{3} \mathrm{PO}_{4}(85 \mathrm{wt} \%$ sol. in water; pro analyze; Janssen Chimica) and bidistilled water under stirring until complete dissolution. Pseudoboehmite (Capatal alumina; $70 \% \quad \mathrm{Al}_{2} \mathrm{O}_{3}$ and $30 \%$ $\mathrm{H}_{2} \mathrm{O}$; Vista) was added under stirring, followed by the dropwise addition of triethylamine (99\%; Janssen Chimica). To control the exothermicity of the reaction, all the reagentia were mixed in an ice bath at 273 $\mathrm{K}$. The obtained homogeneous gel was stirred for $1 \mathrm{~h}$ and then transferred to a Teflon bottle of $50 \mathrm{ml}$, which was inserted in a stainless-steel autoclave. The synthesis was performed statically at 423 or $448 \mathrm{~K}$. After synthesis, the light green material was washed five times with distilled water and dried at $333 \mathrm{~K}$.

Four series of CrAPO-5 samples were prepared: 
Table 1 Overview of the notations, synthesis conditions, and gel compositions of the samples

\begin{tabular}{|c|c|c|c|c|c|c|}
\hline \multirow[b]{2}{*}{ Sample name } & \multicolumn{3}{|c|}{$\begin{array}{c}\text { Gel composition: } \\
0.75 R \cdot\left(\mathrm{Cr}_{x} \mathrm{Al}_{y} \mathrm{P}_{2}\right) \mathrm{O}_{4} \cdot 20 \mathrm{H}_{2} \mathrm{O} \text {, with } R \\
\text { the template molecule triethylamine }\end{array}$} & \multirow{2}{*}{$\begin{array}{c}\mathrm{pH} \text { of the } \\
\text { precursor gel }\end{array}$} & \multirow{2}{*}{$\begin{array}{c}\text { Synthesis } \\
\text { temperature (K) }\end{array}$} & \multirow[b]{2}{*}{$\begin{array}{l}\text { Synthesis } \\
\text { time (h) }\end{array}$} \\
\hline & $x$ & $y$ & $z$ & & & \\
\hline CrA(III) 0.00 & 0.00 & 1.00 & 1.00 & 2.35 & 423 & 168 \\
\hline CrA(III) 0.002 & 0.002 & 0.998 & 1.00 & 2.34 & 423 & 168 \\
\hline CrA(III) 0.004 & 0.004 & 0.996 & 1.00 & 2.34 & 423 & 168 \\
\hline CrA(III)0.02 & 0.02 & 0.98 & 1.00 & 2.30 & 423 & 168 \\
\hline CrA(III) 0.04 & 0.04 & 0.96 & 1.00 & 2.24 & 423 & 168 \\
\hline CrA(III) 0.08 & 0.08 & 0.92 & 1.00 & 1.65 & 423 & 168 \\
\hline $\mathrm{CrC}(I I I) 1$ & 0.02 & 0.98 & 1.00 & 2.30 & 423 & 1 \\
\hline $\mathrm{CrC}(I I I) 2$ & 0.02 & 0.98 & 1.00 & 2.31 & 423 & 2 \\
\hline CrC(III) 5 & 0.02 & 0.98 & 1.00 & 2.31 & 423 & 5 \\
\hline $\mathrm{CrC}(\mathrm{III}) 15$ & 0.02 & 0.98 & 1.00 & 2.30 & 423 & 15 \\
\hline $\mathrm{CrC}(\mathrm{III}) 30$ & 0.02 & 0.98 & 1.00 & 2.30 & 423 & 30 \\
\hline $\mathrm{CrC}(\mathrm{III}) 72$ & 0.02 & 0.98 & 1.00 & 2.29 & 423 & 72 \\
\hline $\mathrm{CrC}(I I I) 168$ & 0.02 & 0.98 & 1.00 & 2.30 & 423 & 168 \\
\hline $\mathrm{CrB}(\mathrm{III}) 0.01$ & 0.01 & 0.99 & 1.00 & 2.32 & 448 & 168 \\
\hline CrB(III)0.02 & 0.02 & 0.98 & 1.00 & 2.30 & 448 & 168 \\
\hline $\operatorname{Cr}(\mathrm{VI})$ & 0.02 & 1.00 & 0.98 & 2.15 & 423 & 168 \\
\hline
\end{tabular}

$\mathrm{CrA}(\mathrm{III})$ samples, $\mathrm{CrB}(\mathrm{III})$ samples, $\mathrm{CrC}(\mathrm{III})$ samples, and a $\mathrm{Cr}(\mathrm{VI})$ sample. The $\mathrm{CrA}(\mathrm{III}), \mathrm{CrB}(\mathrm{III})$, and $\mathrm{CrC}$ (III) samples were prepared with $\mathrm{Cr}\left(\mathrm{NO}_{3}\right)_{3} \cdot 9 \mathrm{H}_{2} \mathrm{O}$ (pro analyze; UCB), whereas the $\mathrm{Cr}$ (VI) sample was synthesized with $\mathrm{CrO}_{3}$ (pro analyze, UCB). The synthesis conditions, notations, and gel compositions of all these samples are summarized in Table 1. The CrA(III) samples were autoclaved for $7 \mathrm{~d}$ at $423 \mathrm{~K}$, whereas the $\mathrm{CrB}$ (III) samples were autoclaved at $448 \mathrm{~K}$. The $\mathrm{CrC}(\mathrm{III})$ samples were synthesized with a synthesis time in the range $1-168 \mathrm{~h}$ at $423 \mathrm{~K}$ and the $\mathrm{Cr}(\mathrm{VI})$ sample was autoclaved during $7 \mathrm{~d}$ at $423 \mathrm{~K}$.

The gels used for the centrifugation procedure (see further) were prepared in the same way as were the gels of the CrA(III) samples: Only the template content (with $R=0.50,0.75$, and 1.25) and the $\mathrm{Cr}$ source $\left[\mathrm{Cr}\left(\mathrm{NO}_{3}\right)_{3} \cdot 9 \mathrm{H}_{2} \mathrm{O}\right.$ and $\left.\mathrm{CrO}_{3}\right]$ were varied. $\mathrm{Re}-$ ference samples were prepared by impregnation of a $\mathrm{Cr}\left(\mathrm{NO}_{3}\right)_{3} \cdot 9 \mathrm{H}_{2} \mathrm{O}$ solution on pure AlPO-5 $\left(\mathrm{Cr}^{3+} /\right.$ AlPO-5) and mixing of $\mathrm{Cr}_{2} \mathrm{O}_{3}$ with pure AlPO-5 $\left(\mathrm{Cr}_{2} \mathrm{O}_{3} / \mathrm{AlPO}-5\right)$.

\section{Pretreatments and techniques}

Powder X-ray diffraction (XRD) patterns of the as-synthesized, calcined, and recalcined samples were recorded with an automated Siemens diffractometer, equipped with a Kristalloflex K710 röntgengenerator and a position-sensitive detector of Inel. The assynthesized samples were granulated and the size fraction $0.25-0.40 \mathrm{~mm}$ was loaded in a quartz flow cell with suprasil windows for diffuse reflectance (d.r.s.) and a side arm for electron spin resonance (e.s.r) measurements. E.s.r. and d.r.s. spectra were taken of the as-synthesized and calcined samples and of some reduced samples. The d.r.s. spectra were measured with a u.v.-vis-NIR Cary 5 spectrometer in the range $200-2200 \mathrm{~nm}$ against a halon white standard. Some spectra were converted to the Kubelka-
Munk function and plotted as a function of wavenumbers. E.s.r. spectra were taken at 120 and $300 \mathrm{~K}$ using a Bruker ER 200 D-SRC instrument in X-band at a microwave power of $200 \mu \mathrm{W}$ with a double rectangular TE104 mode cavity. Temperaturedependent measurements were done on a Bruker ESP300E equipment in X-band at the same microwave power between 370 and $120 \mathrm{~K}$. Calcination and recalcination (after reduction) were performed at $823 \mathrm{~K}$ during $5 \mathrm{~h}$ with an $\mathrm{O}_{2}$ flowrate of $3600 \mathrm{ml} / \mathrm{h}$, whereas reduction was done during $30 \mathrm{~min}$ with a $\mathrm{CO}$ flow rate of $1800 \mathrm{ml} / \mathrm{h}$ at $623 \mathrm{~K}$. D.r.s. spectra were also taken from the wet precursor gels as such and after successive centrifugations ( $20 \mathrm{~min}, 5000$ rounds/ min). Vacuo pretreatments were done at $2 \times 10^{-3} \mathrm{~Pa}$ at 298 and $473 \mathrm{~K}$ overnight.

\section{RESULTS}

\section{Spectroscopic characterization of CrAPO-5's as function of the $\mathrm{Cr}$ content, synthesis temperature, and the $\mathrm{Cr}$ precursor molecule}

Figure 1 shows the d.r.s. spectra of $\mathrm{CrA}(\mathrm{III})$ samples (see Table 1) with increasing $\mathrm{Cr}$ content. The spectra of the $\mathrm{CrB}$ (III) samples are the same and will not be shown. All the spectra contain two typical bands of octahedral $\mathrm{Cr}^{3+}$ at 15,900 and $21,800 \mathrm{~cm}^{-1,5,6}$ which increase in intensity with increasing $\mathrm{Cr}$ content. These bands can be assigned to ${ }^{4} A_{2 g} \rightarrow{ }^{4} T_{2 g}\left(v_{1}\right)$ and ${ }^{4} A_{2 g} \rightarrow{ }^{4} T_{1 g}(F)\left(v_{2}\right)$, respectively. The third band $\left[{ }^{4} A_{2 g}\right.$ $\left.\rightarrow{ }^{4} T_{1 g}(P)\right]$ of octahedral $\mathrm{Cr}^{3+}$ occurs around 33,000 $\mathrm{cm}^{-1}$, but is masked by absorptions of the support. The $15,900 \mathrm{~cm}^{-1}$ band has two weak shoulders, which are spin-forbidden transitions $\left({ }^{4} A_{2 g} \rightarrow{ }^{2} E_{g}\right.$ and $\left.{ }^{4} A_{2 g} \rightarrow{ }^{2} T_{1 g}\right) .5,6$ In Figure 2, the intensities of $v_{1}$ are plotted vs. $\mathrm{Cr}$ content. There is a relatively good linear relation, suggesting the presence of only one $\mathrm{Cr}^{3+}$ species. Replacing the $\mathrm{Cr}^{3+}$ salt by $\mathrm{CrO}_{3}$ in the synthesis mixture results also in the formation of a 


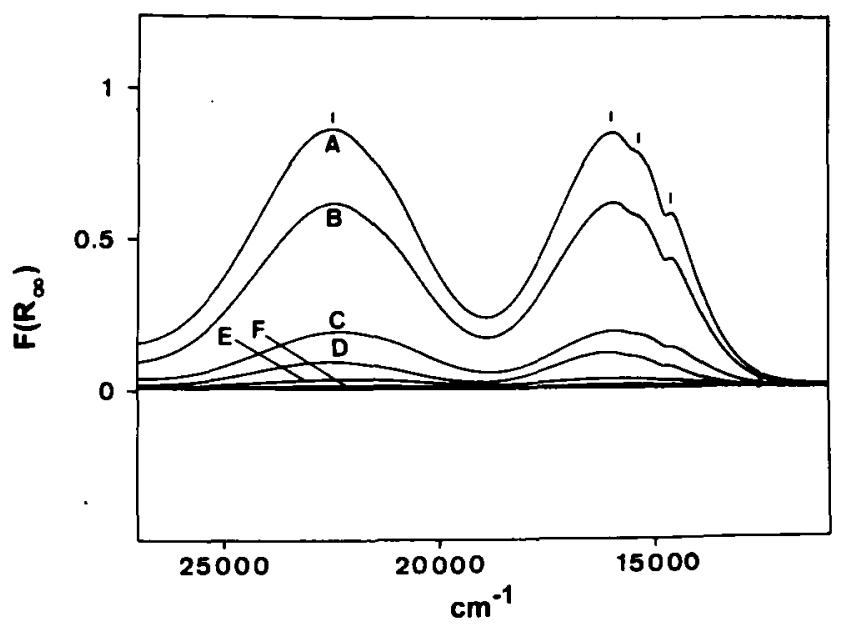

Figure 1 DRS spectra of as-synthesized CrAPO-5 molecular. sieves with increasing $\mathrm{Cr}$ content: $0.75 R \cdot\left(\mathrm{Cr}_{X} \mathrm{Al}_{Y} \mathrm{P}_{z}\right) \mathrm{O}_{4} \cdot 20 \mathrm{H}_{2} \mathrm{O}$ with $x=$ (A) 0.08 , (B) 0.04 , (C) 0.02 , (D) 0.004 , (E) 0.002 , and (F) 0.0 .

green material $[\mathrm{Cr}(\mathrm{VI})$ sample] with spectra identical to those of Figure 1. Therefore, $\mathrm{Cr}^{6+}$ is reduced to $\mathrm{Cr}^{3+}$ during synthesis.

\section{Time dependence of the synthesis}

With the CrC(III) samples, the synthesis was followed as a function of time up to $7 \mathrm{~d}$ by taking samples after $1,2,5,15,30,72$, and $168 \mathrm{~h}$. Some XRD diffractograms are shown in Figure 3. The formation of crystalline material starts after $2 \mathrm{~h}$. The only XRD-detectable product after $5 \mathrm{~h}$ synthesis is AlPO- $\mathrm{H}_{3}$ (Figure $3 B$ ). After $15 \mathrm{~h}, \mathrm{CrAPO}-5$ could be detected (Figure $3 C$ ) and longer synthesis times result in increasing amounts of CrAPO-5. After $72 \mathrm{~h}$, no other crystalline phase than CrAPO- 5 could be monitored and a highly crystalline material is obtained after $7 \mathrm{~d}$ (Figure 3D). The XRD pattern of the calcined CrAPO-5 given in Figure $3 E$ shows that the material is thermally stable.

The corresponding d.r.s. spectra have characteristic absorption bands of octahedral $\mathrm{Cr}^{3+}$ in the $d-d$ region at 629 and $459 \mathrm{~nm}\left(15,900\right.$ and $\left.21,800 \mathrm{~cm}^{-1}\right)$

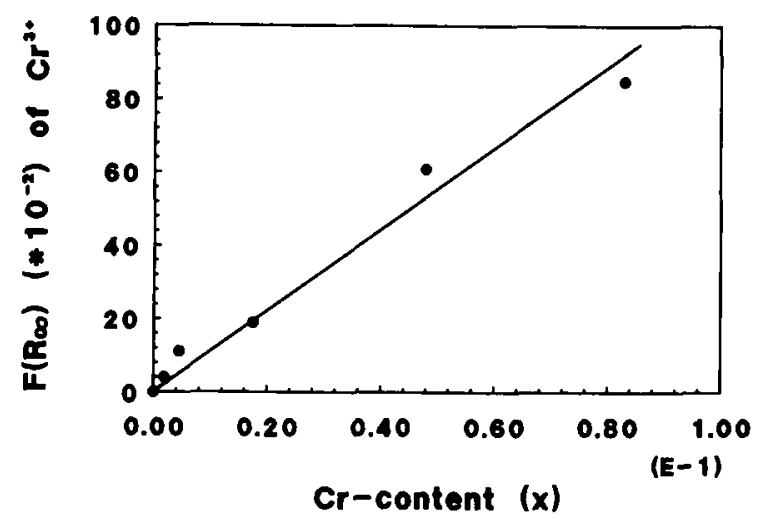

Figure 2 Intensity of the first allowed $d-d$ transition $\left({ }^{4} A_{2 g} \rightarrow\right.$ ${ }^{4} T_{2 g}$ ) vs. the Cr content of CrAPO-5 molecular sieves. of octahedral $\mathrm{Cr}^{3+}$, whatever the synthesis time. The major change occurs in the n.i.r. region: The overtone and combination bands of water decrease with synthesis time or with increasing crystallinity; overtones of $\mathrm{C}-\mathrm{H}$ vibrations of the template increase in intensity and are especially visible in the crystalline product.

\section{Spectroscopic analysis of the wet precursor gels}

In another series of experiments, the influence of the nature of the $\mathrm{Cr}$ precursor and the template content $(R)$ on the retention of $\mathrm{Cr}$ in the gel was investigated. The freshly prepared $\mathrm{CrA}$ (III) gels with different $R$ contents have a light blue color. Figure 4 shows the d.r.s. spectra of the $\mathrm{Cr}(\mathrm{III})-\mathrm{AlPO}-5$ gels with $R=0.75$ before and after centrifugation. The d.r.s. spectra of the gels with other $R$ values are exactly the same. The spectra are characterized by

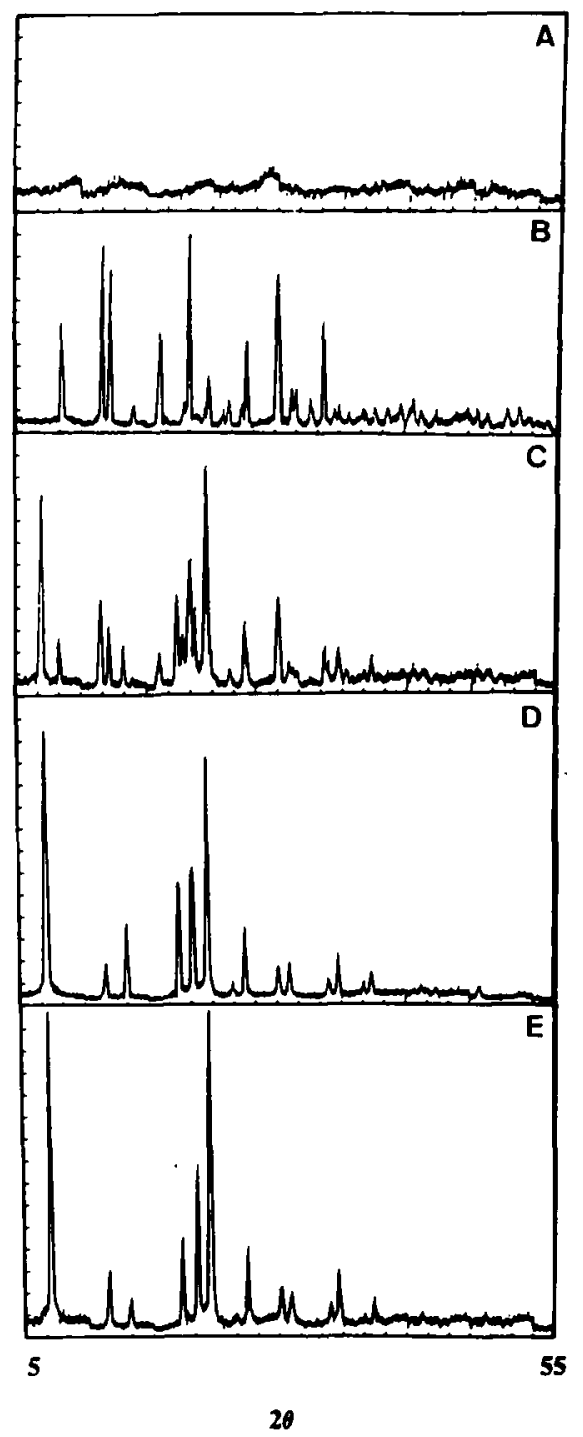

Figure 3 Synthesis of CrAPO-5 as function of time: Evolution of the XRD diffractograms: (A) 1 and $2 h$; (B) $5 h$; (C) $30 h$; (D) $168 \mathrm{~h}$; (E) calcined sample of (D). 


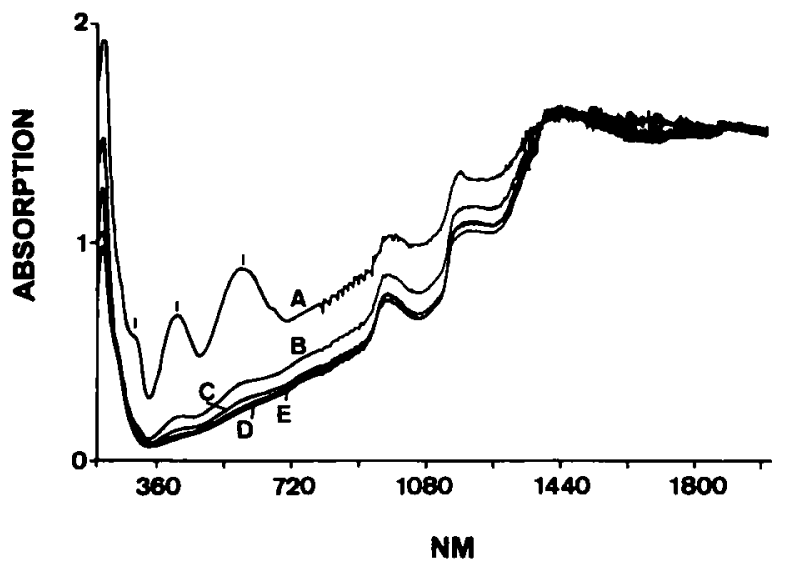

Figure 4 D.r.s. spectra of the $C r(I I I)$ gel with $R=1.25$ : (A) as such; (B) after centrifugation; (C) after $2 \times$ centrifugation; (D) after $3 \times$ centrifugation; $(E)$ after $4 \times$ centrifugation.

three bands at 585,405 , and $297 \mathrm{~nm}(17,100,24,700$, and $\left.33,700 \mathrm{~cm}^{-1}\right)$, typical for octahedral $\mathrm{Cr}^{3+}\left(\mathrm{H}_{2} \mathrm{O}\right)_{6}$ complexes. ${ }^{5,6}$ After centrifugation, the $\mathrm{Cr}^{3+}$ content of the solid decreases and finally disappears almost completely after four washings and centrifugations. This shows that $\mathrm{Cr}^{3+}$ is not incorporated into the solid phase, but can be washed off.

The freshly prepared $\mathrm{Cr}(\mathrm{VI})$ gels are orangeyellow and the corresponding d.r.s. spectra are shown in Figure 5. These spectra are dominated by three intense bands: 444,370 , and $275 \mathrm{~nm}(22,500,27,000$, and $\left.36,400 \mathrm{~cm}^{-1}\right)$. These bands are typical charge transfers of the type $\mathrm{O} \rightarrow \mathrm{Cr}^{6+}$ (Ref. 5) and can be assigned as follows: the symmetry forbidden $1 t_{1} \rightarrow 2 e$ $\left(22,500 \mathrm{~cm}^{-1}\right)$ and two allowed transitions $1 t_{1} \rightarrow 2 e$ $\left(27,000 \mathrm{~cm}^{-1}\right)$ and $6 t_{2} \rightarrow 2 e\left(36,400 \mathrm{~cm}^{-1}\right){ }^{8}$ The $22,500 \mathrm{~cm}^{-1}$ band is typically for dichromate species in solution (but absent in chromates). ${ }^{9}$ Thus, under the $\mathrm{pH}$ conditions of the gel preparation $(\mathrm{pH}$ at around 2$), \mathrm{Cr}$ is present mainly as dichromate. By centrifugation, almost all $\mathrm{Cr}$ is removed from the gel, independently of the $\mathrm{Cr}$ precursor and template content. Therefore, there exists no or only a weak interaction between dichromate and the molecular

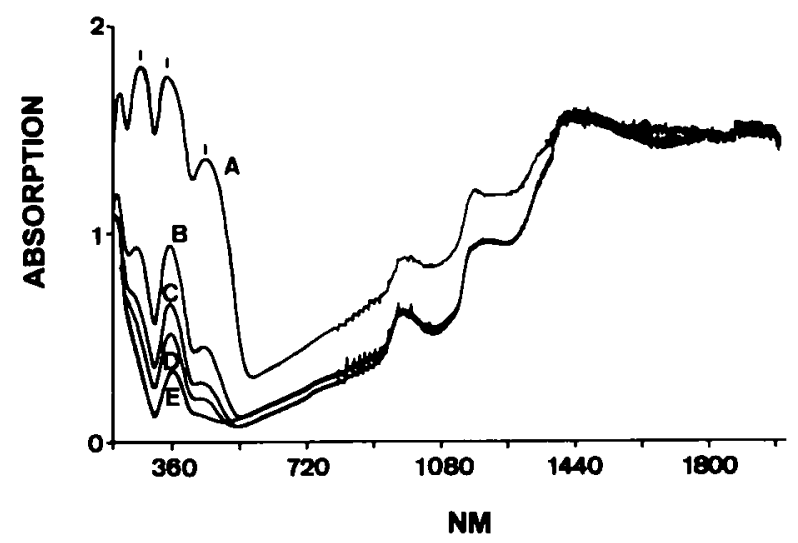

Figure 5 D.r.s. spectra of the $\mathrm{Cr}(\mathrm{VI})$ gel with $R=0.75$ : (A) as such; (B) after centrifugation; (C) after $2 \times$ centrifugation; (D) after $3 \times$ centrifugation; (E) after $4 \times$ centrifugation.

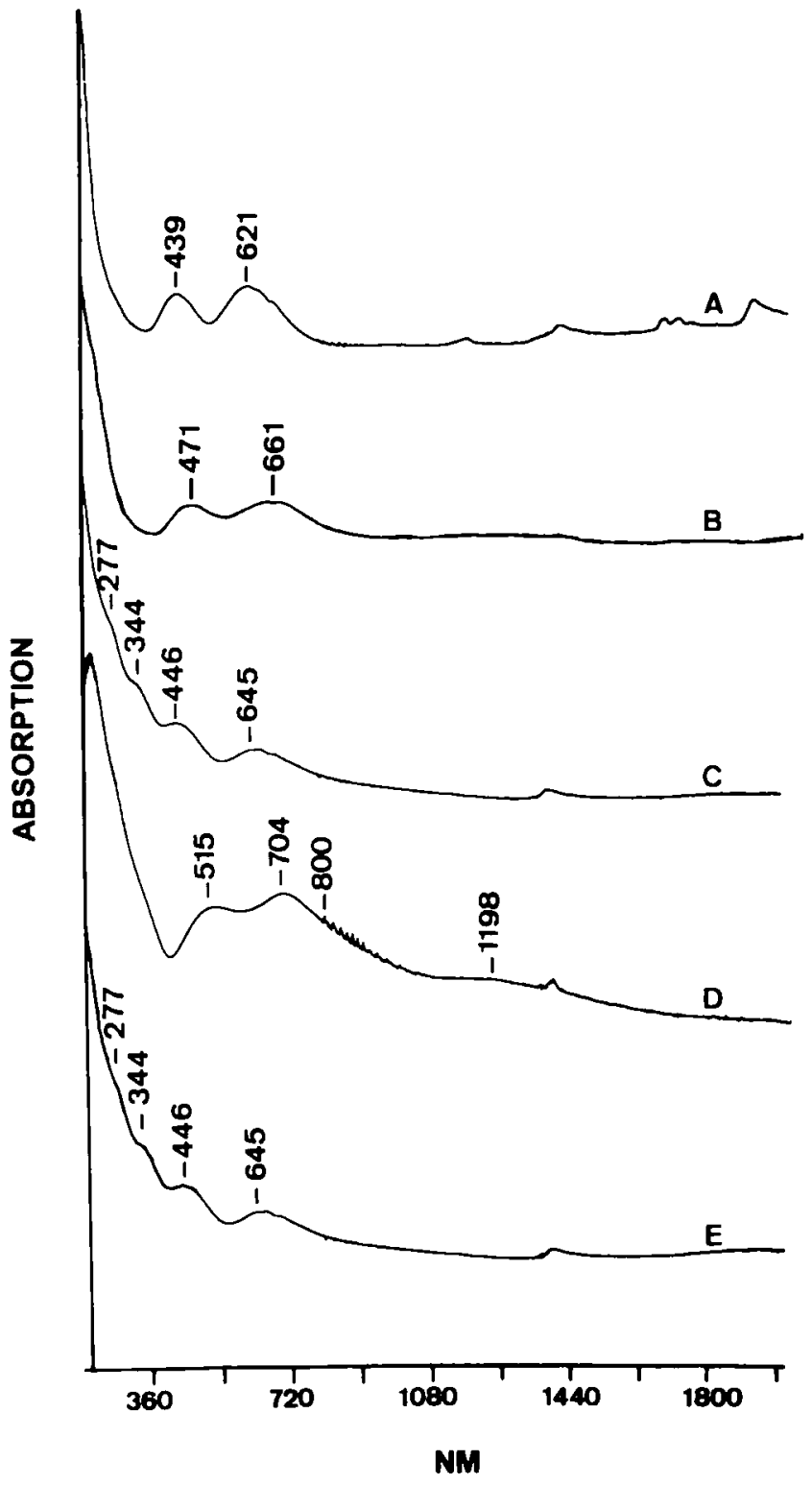

Figure 6 D.r.s. spectra of $\mathrm{CrA}(I I I) 0.02:(\mathrm{A})$ as such; (B) after vacuo pretreatment; (C) after calcination; (D) after reduction; (E) recalcination.

sieve gel. Furthermore, the $22,500 \mathrm{~cm}^{-1}$ band can be more fully eliminated by the centrifugation procedure than can the two other bands (Figure 5). This suggests the presence of dichromate and chromate, the latter interacting more strongly with the gel.

\section{Coordination and chemistry of $\mathbf{C r}$}

Figures 6 and 7 show, respectively, d.r.s. and e.s.r. spectra of $\mathrm{CrA}$ (III) 0.02 , as such, after vacuo pretreatment, calcination, $\mathrm{CO}$ reduction, and recalcination. The e.s.r. spectrum of the as-synthesized CrAPO-5 is dominated by an isotropic signal with $g=1.97$ and ppw (= peak-to-peak width) $=700 \mathrm{G}$ and a weak, broad signal around $g=4.3$. The total intensity follows the Curie-Weiss law. This behavior is comparable with that of $\mathrm{Cr}^{3+}$ impregnated AlPO-5. The 

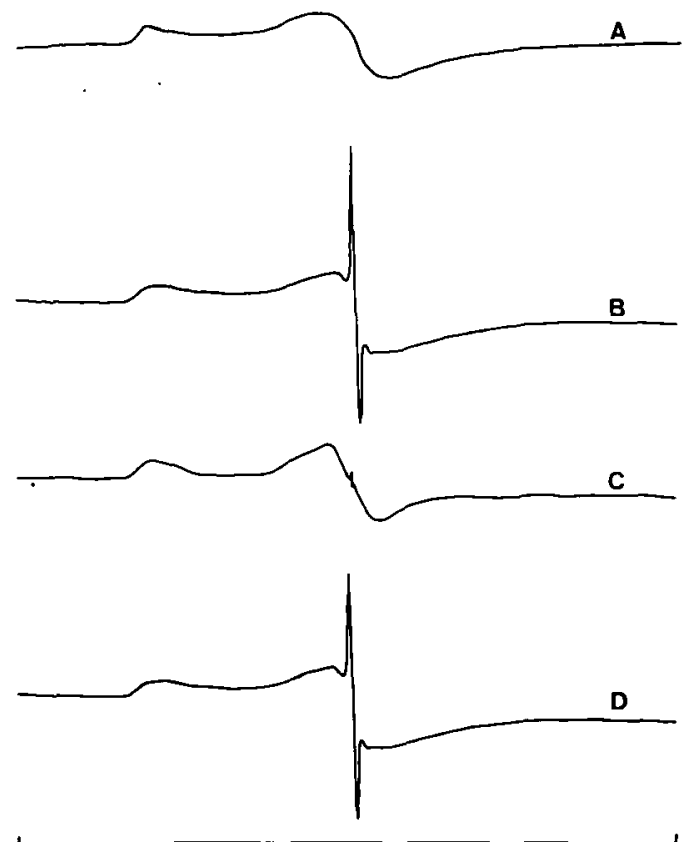

0

6800

G

Figure 7 E.s.r. spectra of $\mathrm{CrA}(\mathrm{III}) 0.02$ (at $300 \mathrm{~K}$ ): (A) as such and after vacuo pretreatment; (B) after calcination; (C) after $\mathrm{CO}$ reduction; (D) after recalcination.

d.r.s. spectra show the typical $d-d$ transitions of octahedral $\mathrm{Cr}^{3+}$.

Vacuum pretreatment of the sample at $20^{\circ} \mathrm{C}$ shifts the $d-d$ transitions of octahedral $\mathrm{Cr}^{3+}$ to $638 \mathrm{~nm}$ $\left(15,700 \mathrm{~cm}^{-1}\right)$ and $454 \mathrm{~nm}\left(22,000 \mathrm{~cm}^{-1}\right)$. At $200^{\circ} \mathrm{C}$, these bands shift to $661 \mathrm{~nm}\left(14,900 \mathrm{~cm}^{-1}\right)$ and 471 $\mathrm{nm}\left(21,100 \mathrm{~cm}^{-1}\right)$, but no new absorption bands at the low energy of tetrahedral $\mathrm{Cr}^{3+}$ are observed. The e.s.r. spectra are the same as after synthesis.

After calcination, the color of the sample turns to yellow-green and both e.s.r. and d.r.s. spectra are totally changed. Two new bands in the u.v. appear at 344 and $277 \mathrm{~nm}\left(29,100\right.$ and $\left.36,100 \mathrm{~cm}^{-1}\right)$ at the expense of the two $d-d$ transitions of $\mathrm{Cr}^{3+}$. These u.v. bands are the two charge-transfer transitions $\mathrm{O} \rightarrow$ $\mathrm{Cr}^{6+}\left(d^{0}\right)$. Thus, part of the $\mathrm{Cr}^{3+}$ is oxidized to a chromatelike species. The e.s.r. spectra show a new strong and narrow signal with axial symmetry $\left(g_{\perp}=\right.$ 1.99 and $g \mid=1.90$; ppw $=45 \mathrm{G}$ ) superimposed on the broad $g=1.97$ signal. This signal is ascribed to $\mathrm{Cr}^{5+}, 10,11$ and the intensity follows the Curie-Weiss law. The d.r.s. bands of $\mathrm{Cr}^{3+}$ are shifted to, respectively, 645 and $446 \mathrm{~nm}\left(15,500\right.$ and $\left.22,400 \mathrm{~cm}^{-1}\right)$. The intensity of the corresponding e.s.r. spectrum (Figure 7) does not follow the Curie-Weiss law. This is mainly due to the broadening of the $g=1.97$ signal upon decrease of temperature. Also, the $g=4.3$ signal is broadened by the calcination treatment on its high field side, but otherwise not much affected.

After $\mathrm{CO}$ reduction, the sample is blue-purple, almost all $\mathrm{Cr}^{5+}$ has disappeared, and the e.s.r. spectrum is nearly the same as before calcination. The d.r.s. spectrum is dominated by two bands at 704 and
$515 \mathrm{~nm}\left(14,200\right.$ and $\left.19,400 \mathrm{~cm}^{-1}\right)$, the former asymmetric at lower wavelength $\left(800 \mathrm{~nm}\right.$ or $\left.12,500 \mathrm{~cm}^{-1}\right)$. Also, a weak and broad absorption at $1198 \mathrm{~nm}(8350$ $\mathrm{cm}^{-1}$ ) is visible. The former two bands can be ascribed to (distorted) octahedral $\mathrm{Cr}^{3+}$. The asymmetric shoulder is due to octahedral $\mathrm{Cr}^{2+}$, because octahedral complexes of a high spin $3 d^{4}$, such as $\mathrm{Cr}^{2+}$, show a single spin-allowed $d-d$ transition in that region: ${ }^{5} E_{g} \rightarrow{ }^{5} T_{2 g} .{ }^{12}$ The broad and weak band at $1198 \mathrm{~nm}$ can be attributed to (distorted) tetrahedral $\mathrm{Cr}^{2+}$ complexes. ${ }^{5}$ Thus, $\mathrm{Cr}^{6+}$ and $\mathrm{Cr}^{5+}$ are reduced to $\mathrm{Cr}^{3+}$ and minor amounts of $\mathrm{Cr}^{2+}$. Recalcination gives the same spectra as after the first calcination and the color of the sample turns to yellow-green.

\section{DISCUSSION}

\section{Chromium in CrAPO-5}

In the gels, $\mathrm{Cr}^{3+}$ is present as an octahedral aquocomplex, while $\mathrm{Cr}^{6+}$ is mainly a dichromatelike species. This chromium has, irrespective of synthesis procedure and $\mathrm{Cr}$ precursors, only a small affinity for the gel components and is mainly present in the liquid phase.

Our main goal is to see if $\mathrm{Cr}$ can be incorporated into the framework of AlPO-5. The criteria for structural $\mathrm{Cr}$ are (1) tetrahedral coordination, (2) a ligand field strength typically for an oxygen environment, and (3) a linear increase of band intensities with the $\mathrm{Cr}$ content.

The d.r.s. spectra of the as-synthesized (green) materials are, irrespective of the synthesis time and procedure, typical for octahedral $\mathrm{Cr}^{3+}$ and, therefore, the first criterion for structural $\mathrm{Cr}$ is not fulfilled. One can use the centers of the band system to calculate the octahedral ligand field strength and the ligand field parameter $B$ with standard procedures. ${ }^{5,13}$ The results are shown in Table 2 and compared with $\mathrm{Cr}^{3+}$ impregnated AIPO-5, a physical mixture of $\mathrm{Cr}_{2} \mathrm{O}_{3}$ and AlPO-5 and literature data of octahedral $\mathrm{Cr}^{3+}$ with an oxygen environment. These data show that the ligand field strength of $\mathrm{Cr}^{3+}$ in CrAPO-5 is somewhat lower, but similar to those of reference compounds with $\mathrm{Cr}^{3+}$ surrounded by six oxygen ligands and, therefore, the second criterion is fulfilled. From Figure 2, it follows that the third criterion is obeyed. In the as-synthesized samples, e.s.r. also shows the presence of octahedral hexa-aquo $\mathrm{Cr}^{3+}$ ions, which have the same behavior as that of $\mathrm{Cr}^{3+}$ ions impregnated on pure AlPO-5.

Thus, during synthesis, there is no indication for a transformation of the octahedral coordination to a tetrahedral one, with an expected absorption around $7500 \mathrm{~cm}^{-1}[10 \mathrm{Dq}$ (tetrahedral) $=(4 / 9) \times 10 \mathrm{Dq}$ (octahedral)]. Also, the octahedral $\mathrm{Cr}^{3+}$ cannot be transformed to tetrahedral $\mathrm{Cr}^{3+}$ by vacuum pretreatment. The latter treatment induces a slight shift of the octahedral bands to lower energy. The resulting reduction in ligand field strength (Table 2) indicates the change of the environment of the $\mathrm{CrO}_{6}$ moiety. We have no unambiguous experimental evidence to propose an octahedral lattice $\mathrm{Cr}^{3+}$ species. Also, in 
Table 2 Ligand field strength, $10 \mathrm{Dq}$, and Racah's interelectronic repulsion parameter, $B$, for $\mathrm{Cr}^{3+}$ in octahedral environment of oxygen atoms

\begin{tabular}{lccc}
\hline Compound & $10 \mathrm{Dq}\left(\mathrm{cm}^{-1}\right)$ & $B$ & Refs. \\
\hline As-synthesized CrAPO-5 & 15,900 & 577 & \\
Vacuum-pretreated CrAPO-5 $20^{\circ} \mathrm{C}$ & 15,700 & 631 & This work \\
Vacuum-pretreated CrAPO-5 $200^{\circ} \mathrm{C}$ & 14,900 & 629 & This work \\
Cr ${ }^{3+}$ impregnated AlPO-5 & 17,100 & 712 & This work \\
$\mathrm{Mixture}^{-1} \mathrm{Cr}_{2} \mathrm{O}_{3}$ and AlPO-5 & 16,800 & 423 & This work \\
$\alpha-\mathrm{Al}_{2} \mathrm{O}_{3}\left(\mathrm{Cr}^{3+}\right)$ & 18,000 & 643 & 6 \\
$\alpha-\mathrm{Cr}_{2} \mathrm{O}_{3}\left(\mathrm{Cr}^{3+}\right)$ & 16,650 & 624 & 6 \\
$\mathrm{Cr}_{2} \mathrm{O}_{3}$ & 16,600 & 468 & \\
$\mathrm{MgAl}_{2} \mathrm{O}_{4}\left(\mathrm{Cr}^{3+}\right)$ & 18,000 & 670 & \\
$\mathrm{MgCr}_{2} \mathrm{O}_{4}$ & 17,150 & 633 & 6 \\
$\mathrm{YCrO}_{3}$ & 16,450 & 542 & 6 \\
$\mathrm{LiCrO}_{2}$ & 17,300 & 615 & 6 \\
\hline
\end{tabular}

dehydrated pure AlPO-5, no octahedral $\mathrm{Al}^{3+}$ can be found by n.m.r.

In summary, our results prove that $\mathrm{Cr}^{3+}$ is octahedrally coordinated in the initial gel, during synthesis and after synthesis. The question arises why there is no tendency for $\mathrm{Cr}^{3+}$ to change to the tetrahedral coordination, necessary for isomorphous substitution in the AlPO- 5 molecular sieves. A strong argument can be found in the crystal field stabilization energy (CFSE) of octahedral $(224.5 \mathrm{~kJ} / \mathrm{mol}) \mathrm{vs}$. tetrahedral $\mathrm{Cr}^{3+}(66.9 \mathrm{~kJ} / \mathrm{mol}) .{ }^{14}$ This suggests that a $d^{3}$ ion, like $\mathrm{Cr}^{3+}$, has a too strong preference for the octahedral relative to the tetrahedral coordination ${ }^{15}$ to be forced in tetrahedral coordination under synthesis conditions.

\section{Chemistry of CrAPO-5}

The spectral changes upon calcination are (1) the appearance of two new bands in d.r.s. which are typically for $\mathrm{Cr}^{6+}$; (2) the appearance of a new species, $\mathrm{Cr}^{5+}$, in e.s.r; (3) the shifts of the $\mathrm{Cr}^{3+}$ bands in d.r.s. with respect to as-synthesized CrAPO-5; and (4) the nondependence of the 1.97 signal on the Curie-Weiss law. Thus, the oxidation of $\mathrm{Cr}^{3+}$ is not complete. Reduction with $\mathrm{CO}$ at $623 \mathrm{~K}$ is easy with formation of $\mathrm{Cr}^{3+}$ and some $\mathrm{Cr}^{2+}$. Oxidation regenerates the initial calcined state. This behavior of CrAPO-5 upon calcination and $\mathrm{CO}$ reduction is similar to that of $\mathrm{Cr}$ supported on amorphous supports. 8.16

$\mathrm{Cr}^{5+}$ can only be detected in e.s.r. by its axial symmetric signal around $g=1.97$. The signal can be reversible regenerated by successive calcinations and reduction and the intensity follows the Curie-Weiss law. This signal is attributed to isolated $\mathrm{Cr}^{5+}$ and has typical line widths of $\mathrm{Cr}^{5+}$ on amorphous supports $(\gamma$ signal). ${ }^{10,11}$ However, the distinction between lattice and extralattice $\mathrm{Cr}^{5+}$ cannot be made.

The coordination of $\mathrm{Cr}^{3+}$ can be evaluated by d.r.s. and e.s.r. The broad $g=1.97$ signal in e.s.r. can be assigned to $\mathrm{Cr}_{2} \mathrm{O}_{3}$ clusters. Although the Neél temperture of $\alpha-\mathrm{Cr}_{2} \mathrm{O}_{3}$ is $307 \mathrm{~K},{ }^{17}$ mostly no clear Neél temperature is observed for supported $\mathrm{Cr}$ clusters, indicating amorphous clusters of different particle size. The broadening of the signal with decreasing temperature suggests the presence of $\mathrm{Cr}^{3+}$ ions strongly interacting in a dispersed $\mathrm{Cr}_{2} \mathrm{O}_{3}$ phase. Thus, the observation of this signal indicates small clusters with properties that deviate from bulk $\mathrm{Cr}_{2} \mathrm{O}_{3}$ properties, a situation not uncommon for supported metallic and oxidic particles ( $\beta$-signal on amorphous supports) ${ }^{10,11,16}$ The shifts of the octahedral d.r.s. bands of $\mathrm{Cr}^{3+}$, with respect to the as-synthesized CrAPO-5, support this view. Therefore, these signals are due to nonincorporated octahedral $\mathrm{Cr}^{3+}$.

Finally, the $g=4.3$ signal must be addressed. The pure AlPO- 5 also has this absorption, which must be due to $\mathrm{Fe}^{3+}$ impurities of the $\mathrm{Al}$ source. Thus, pseudotetrahedral $\mathrm{Fe}^{3+}$ is the usual assignment, but in view of the work of Nakamura et al., ${ }^{18}$ latticesubstituted $\mathrm{Cr}^{3+}$ cannot be excluded. Also, Mosser et al. ${ }^{19}$ proved the incorporation of pseudo-octahedral $\mathrm{Cr}^{3+}$ in kaolinite, which gives a $g=4.3$ signal in e.s.r. Furthermore, in the extensive e.s.r. literature on Cr-supported catalysts, a broad absorption in the range $g=3-4.5$ is reported ( $\delta$ phase), which is attributed to isolated $\mathrm{Cr}^{3+} .{ }_{16,20,21}$ Such isolated $\mathrm{Cr}^{3+}$ is in (pseudo-)octahedral coordination and located on the surface. Nevertheless, the $g=4.3$ signal can only be due to pseudotetrahedral $\mathrm{Fe}^{3+}$ or pseudooctahedral $\mathrm{Cr}^{3+}$ and is present in small quantities. If it is due to pseudo-octahedral $\mathrm{Cr}^{3+}$, this $\mathrm{Cr}$ must be located at the surface, because no octahedral $\mathrm{Al}$ sites are available for $\mathrm{Cr}$ in dehydrated AlPO-5.

In summary, our results clearly show the following:

1. The affinity of the Cr-ions for the gel is small.

2. No tetrahedral $\mathrm{Cr}^{3+}$ can be found.

3. There is spectroscopic resemblance between $\mathrm{Cr}^{3+}$ impregnated AlPO-5 and CrAPO-5.

4. The redox chemistry of $\mathrm{Cr}$ in CrAPO-5 is similar to that of Cr-supported catalysts.

All this supports the idea of nonincorporation of $\mathrm{Cr}$ into the lattice of AlPO-5.

\section{CONCLUSIONS}

In the gels of CrAPO- 5 molecular sieves, $\mathrm{Cr}$ is present as an octahedral $\mathrm{Cr}$-aquo complex $\left(\mathrm{Cr}^{3+}\right)$ or dichromate $\left(\mathrm{Cr}^{6+}\right)$. These ions are present in the liquid phase of the gel and can be easily washed off. During 
and after synthesis, $\mathrm{Cr}$ is present as $\mathrm{Cr}^{3+}$ in octahedral coordination to oxygens and this $\mathrm{Cr}^{3+}$ cannot be transformed to tetrahedral $\mathrm{Cr}^{3+}$ upon vacuum pretreatment. Thus, no structural $\mathrm{Cr}$ is found in $\mathrm{CrAPO}-5$ molecular sieves. The CFSE of octahedral vs. tetrahedral $\mathrm{Cr}^{3+}$ explains why $\mathrm{Cr}$ cannot be transformed from octahedral to tetrahedral during synthesis. This $\mathrm{Cr}^{3+}$ is partially oxidized by calcination to chromate and $\mathrm{Cr}^{5+}$. $\mathrm{CO}$ reduction results in the formation of octahedral $\mathrm{Cr}^{3+}$ and octahedral and tetrahedral $\mathrm{Cr}^{2+}$, whereas recalcination restores the $\mathrm{Cr}^{5+}$ and $\mathrm{Cr}^{6+}$ species.

\section{ACKNOWLEDGEMENTS}

B.M.W. acknowledges the N.F.W.O. (Nationaal Fonds voor Wetenschappelijk Onderzoek) for a grant as a research assistant. This work was financially supported by the Fonds voor Kollectief Fundamenteel Onderzoek (FKFO) under Grant 2.0050.93.

\section{REFERENCES}

1 Wilson, S.T., Lok, B.M., Messina, C.A., Gajek, R.T., Patton, R.L. and Flanigen, E.M. J. Am. Chem. Soc. 1982, 104, 1146

2 Tielen, M., Geelen, M. and Jacobs, P.A. Acta Phys. Chem. Szeged. 1985, 1

3 Flanigen, E.M., Patton, R.L. and Wilson, S.T. Innovation in Zeolite Materials Science (Eds. P.J. Grobet, W.J. Mortier,
E.F. Vansant and G. Schulz-Ekloff) Elsevier, Amsterdam, 1988, p. 13

4 Flanigen, E.M., Lok, B.M.T., Patton, L. and Wilson, S.T. US Pat. 4759919 (1988)

5 Lever, A.B.P. Inorganic Electronic Spectroscopy, 2nd ed., Elsevier, Amsterdam, 1984

6 Reinen, D. Struct. Bond. 1969, 6, 30

7 Rajic, N., Stojakovic, D., Hocevar, S. and Kaucic, V. Zeolites 1993, 13, 384

8 Szabo, Z.G., Kamaras, K., Szebeni, S. and Ruff, I. Spectrochim. Acta 1978, 34a, 607

9 Weckhuysen, B.M., De Ridder, L.M. and Schoonheydt, R.A. J. Phys. Chem. 1993, 97, 4756

10 O'Reilly, D.E. and Maclver, D.S. J. Phys. Chem. 1962, 66, 276

11 van Reijen, L.L. and Cossee, P. Disc. Faraday Soc. 1966, 41, 277

12 Fackler, J.P. and Holah, D.G. Inorg. Chem. 1975, 4, 954

13 König, E. Struct. Bond. 1971, 9, 175

14 West, A.R. Basic Solid State Chemistry, Wiley, Chichester, 1988

15 Reinen, D. Z. Anorg. Allgem. Chem. 1968, 356, 172

16 (a) McDaniel, M.P. Adv. Catal. 1985, 33, 47. (b) Weckhuysen, B.M., Verberckmoes, A.A., Buttiens, A.L. and Schoonheydt, R.A. J. Phys. Chem. 1994, 98, 579

17 Kittel, C.H. Introduction to Solid State Physics, 3rd ed., Wiley, New York, 1968

18 Nakamura, O., Mambrim, J.S.T., Pastore, H.O., Vichi, E.J.S., Gandra, F.G., da Silva, E.C., Vargas, H. and Pelzi, J. J. Chem. Soc., Faraday Trans. 1992, 88(14), 2017

19 Mosser, C., Petit, S. and Mestdagh, M. Clay Miner. 1993, 28, 353

20 Poole, C.P. and Maclver, D.S. Adv. Catal. 1967, 17, 223

21 Groeneveld, C., Wittgen, P.P.M.M., van Kersbergen, A.M., Mestrom, P.L.M., Nuijten, C.E. and Schuit, G.C.A. J. Catal. $1979,59,153$ 